\title{
A Indústria Automobilística no Brasil e a Demanda de Veículos no Período 2000-2010
}

\section{The Automotive Industry in Brazil and its Demand of Vehicles in the Period 2000-2010}

Luciano Ferreira Gabriel*

Resumo: O presente artigo tem como objetivo geral realizar uma análise da indústria automobilística no Brasil contrastando o cenário de produção nacional com o internacional no período recente (até 2010), bem como verificar a influência de algumas variáveis selecionadas sobre a demanda de veículos automotores no mercado interno. Constatou-se que a China e Índia estão moldando os padrões de concorrência internacional no período recente. Além disso, entre um conjunto de variáveis testadas econometricamente, infere-se que a demanda de veículos automotores no mercado interno tem sofrido maior influência dos fatores preço, volume de financiamentos e taxas de juros (operações de crédito com recursos livres referenciais para taxa de juros pré-fixada) no período analisado.

Palavras-chave: Indústria automobilística. Demanda. China. Crédito.

Abstract: The general objective of this paper is to analyze the Brazilian automobile industry in the national scenario and in the international context until 2010. Besides, it will be tested some variables regarding the national vehicles demand. It was verified that China and India are shaping the international standard of competition in the recent period. Among a group of variables econometrically tested, the results suggest a significant influence of prices, financial volume and the pre fixed interest rate credit resources to finance the vehicles acquisitions in the period studied.

Keywords: Automobile industry. Demand. China and Credit.

JEL Classification: L00; L13; L62.

Doutorando em Economia pelo CEDEPLAR-UFMG. Professor de Economia do Centro Universitário UNA, membro do grupo de pesquisa do $\mathrm{CNPq}(\mathrm{UnB})$ sobre macroeconomia estruturalista do desenvolvimento. E-mail: lucianofg@gmail.com 


\section{Introdução}

De acordo com dados da Organização Internacional dos Fabricantes de Veículos Automotores (Oica), a indústria automobilística movimentou cerca de US $\$ 2,5$ trilhões em 2005. Nesse contexto, se a indústria automotiva fosse um país, possuiria o sexto maior PIB mundial.

Essa indústria possui importantes encadeamentos produtivos sobre outros setores. Em Casotti e Goldenstein (2008), observa-se que 50\% do total de borracha, $25 \%$ do total de vidro e $15 \%$ do total de aço produzidos no mundo se destinam a essa indústria, em especial. Para movimentar esse setor, mais de oito milhões de funcionários estão empregados diretamente e, para cada emprego direto, mais de cinco indiretos são gerados, se computados no cálculo o setor de autopeças.

O setor automotivo tem na montagem de veículos sua principal atividade e caracteriza-se como um oligopólio global, formado por um pequeno número de grandes empresas internacionalizadas, organizadas em diversas aglomerações produtivas em diferentes países. Os elevados ganhos de economia de escala e de aglomeração, entre outras barreiras à entrada no processo de produção de um automóvel, são fundamentais para a compreensão do comportamento desse mercado.

Em Ferraz, Kupfer e Haguenaur (1996) e Casotti e Goldenstein (2008), esse setor está em permanente processo de consolidação, sendo frequentes as incorporações, fusões, joint ventures e parcerias comerciais das mais diversas naturezas que, de uma forma geral, reafirmam a estrutura de mercado oligopolizado desse setor econômico.

Além desse oligopólio global ter grande importância na economia, as empresas do setor têm sido precursoras no desenvolvimento de novas tecnologias, bem como no desenvolvimento de novos modelos de gestão fabril, como apontam Casotti e Goldenstein (2008).

O Brasil, de uma maneira geral, apresenta um grande mercado doméstico efetivo e potencial, completo parque industrial, sólida base de engenharia relacionada à indústria automotiva e uma rede de concessionários com grande capilaridade nacional.

Ao analisar a distribuição geográfica da produção de veículos no Brasil e a participação no mercado das principais montadoras, percebem-se claramente as características citadas anteriormente. Ou seja, quatro das principais montadoras de veículos no Brasil respondem por aproximadamente $82,53 \%$ da produção, as quais estão basicamente concentradas em regiões metropolitanas dos Estados do Sul e Sudeste do Brasil. ${ }^{1}$

1 Informação calculada a partir de dados da Anfavea (2010), envolvendo a produção de 2009 de autoveículos da Fiat, Ford, GM e Volkswagem. 
Este artigo tem como objetivo geral realizar uma análise da indústria automobilística no Brasil contrastando o cenário nacional com o internacional no período recente (até 2010), bem como verificar a influência de algumas variáveis selecionadas (salário, preço, taxa de juros e volume de crédito) sobre a demanda de veículos automotores no mercado interno (as séries temporais utilizadas vão de junho de 2000 a outubro de 2010).

Para cumprir esse objetivo, o presente artigo está divido em mais cinco seções, além desta introdução. Na seção 2 é feita uma apresentação da relação do setor automotivo e os demais setores de atividade econômica. Na seção 3 é realizada uma análise a respeito da produção doméstica e o mercado internacional. Na Seção 4 é realizada uma estimativa da demanda de autoveículos no Brasil de junho de 2000 a outubro de 2010 a partir de uma abordagem econométrica. Na seção 5 é realizada uma análise da demanda de veículos automotores no período recente em termos dos fatores crédito e juros. E, na seção 6, por fim, são apresentadas as considerações finais.

\section{A Dinâmica do Setor Automotivo e a Relação com os demais Setores da Economia}

De acordo com Santos e Pinhão (1999), a produção de veículos no Brasil teve início no final da década de 1950, com a implantação de fábricas como Volkswagem, Toyota, Ford (automóveis e comerciais leves), Mercedez Benz, Scania (caminhões e ônibus), na cidade de São Bernado do Campo, General Motors (automóveis, comerciais leves, caminhões ônibus), em São Caetano do Sul, e Ford (caminhões), na cidade de São Paulo.

A partir de Camargo e Lemos (2008), bem como de Santos e Pinhão (1999), pode-se observar que as montadoras realizaram seus primeiros movimentos em busca de outras localizações fora da Grande Região do ABCD de São Paulo durante a década de 70, quando a Volkwagen e a Ford, por meio de incentivos de governos municipais se voltaram para a região do Vale do Paraíba na primeira expansão de suas atividades, instalando-se em Taubaté e juntando-se, assim, à General Motors, que já possuía uma fábrica de motores em São José dos Campos.

O setor contou com grandes incentivos do governo federal. No total, onze empresas montadoras se instalaram no país. De acordo com o Instituto Paranaense de Desenvolvimento Econômico e Social - Ipardes (2005), a produção nacional foi de um total de 1.166 unidades de veículos em 1957, crescendo rapidamente até 1959 para 14.495 unidades. A mesma dinâmica se manteve nos anos 1960, quando se iniciaram os primeiros lotes para exportação. Nos anos 1970, o país aumentou consideravelmente sua participação no mercado internacional alcançando, na década seguinte, o seu nível máximo de produção. 
A partir da análise de Santos e Pinhão (1999), ainda naquela época não era interessante sair do Estado de São Paulo, tampouco distanciar-se do grande mercado consumidor da Região Sudeste. No entanto, a Volvo instalou, ainda naquele período, sua fábrica de caminhões e ônibus no Paraná e a Fiat iria para Minas Gerais, apesar de se manterem próximas dos fornecedores de autopeças do Estado de São Paulo.

Durante a década de 1960-1970, Santos e Pinhão (1999) destacam que outros fabricantes mundiais de veículos estiverem presentes no país, produzindo ou licenciando suas marcas, como Renault, Alfa Romeo, DKW, Willis Overland, Chrysler, Dodge, Kharmann-Ghia, Honda e Toyota.

Já na década de 1980, houve alternância entre crescimento e estagnação nas vendas, produção, emprego e investimentos. Tigre et al. (1999² apud IPARDES, 2005) apontam que em 1981 ocorreu forte declínio na produção, com redução de 37\% em relação ao ano anterior. De 1981 até 1984 houve grande retração na produção nacional, e a capacidade ociosa chegou a $27 \%$. Para contornar esse cenário, durante a década de 1980 foram feitos investimentos em processos e produtos e desenvolvidos novos modelos. Além disso, também foram automatizadas algumas linhas de montagem como robotização, solda e pintura. ${ }^{3}$

Na década de 1990, segundo o Ipardes (2005), os países em desenvolvimento foram os principais mercados em que as montadoras internacionais investiram. As

2 TIGRE, P. B. et al. O impacto do Mercosul na dinâmica do setor automotivo. Buenos Aires: BID/ INTAL, 1999.

3 Em relação à década de 1980, de uma maneira geral, pode-se caracterizá-la como um período de instabilidade. Como destaca o Ipardes (2005, p. 30), "Do lado da oferta, em função de constantes conflitos com os fornecedores, as transportadoras e os trabalhadores (1988), conflitos com autoridades econômicas no que se refere aos preços dos veículos (1987-88), entre outros. Além desses fatores, a escassez de petróleo também contribuiu para acentuar o período de crise. Em contrapartida, o governo brasileiro incentivou e pressionou a Petrobrás para desenvolver um novo combustível totalmente nacional durante esta época. O resultado do esforço foi o desenvolvimento de um combustível alternativo, o álcool." 
montadoras japonesas intensificaram seus investimento na Ásia e as dos Estados Unidos e Europa na América Latina. ${ }^{4}$

A estrutura de mercado da indústria automobilística é um oligopólio em nível internacional, possuindo grandes barreiras à entrada (como escala de produção elevada e imobilização de recursos financeiros).

$\mathrm{Na}$ fase atual, o mercado relacionado à indústria automobilística apresenta grande nível de concorrência em função da saturação em alguns mercados e à sua maturidade. Essa característica faz com que as grandes empresas busquem novas oportunidades de crescimento e lucro (SENHORAS, 2005) em países emergentes como o Brasil.

Entre as principais estratégias adotadas por essas empresas, dadas essas características, tem-se na busca por diferenciação de produtos, associações, alianças e, principalmente, a internacionalização das suas atividades. Além disso, o Ipardes (2005, p. 29) destaca a inversão de recursos para a modernização da produção, a comercialização e distribuição de veículos, bem como Fusões e Aquisições (FEBA) que têm reconfigurado o controle de grandes grupos. ${ }^{5}$

Para se ter uma ideia de concentração desse oligopólio, em 2005, seis empresas respondiam por $75 \%$ da produção global de veículos. Em 2009, esse oligopólio ficou menos concentrado, quando essas seis empresas responderam por $53,11 \%$ da produção global, conforme a Tabela 1 .

4 Salerno et al. (2002, p. 4) destacam que: "A promessa de crescimento da demanda em países emergentes (entre os quais o Brasil, Argentina e México, mas também ícones mais significativos de mercados até então pouco acessíveis e potencialmente decisivos, como a China, Rússia, Índia) levou as grandes empresas do setor a um processo intenso e concentrado de internacionalização. O Brasil foi um dos países que mais recebeu unidades industriais de montadoras, seja de novas entrantes como Renault, Mercedes-Benz (automóveis), Chrysler (à época), PSA-Peugeot/ Citroën, 4 unidades pequenas da Honda, Toyota e Mitsubishi, seja de novas fábricas da VW, VW Caminhões (atual VW Veículos Comerciais), Ford, GM, além da forte remodelação de unidades já existentes de todas as empresas já aqui localizadas. Associada a essa onda de novos investimentos, ocorre a entrada de novas empresas do setor de autopeças, seja através da instalação de plantas novas, para atender à demanda para a produção de novos modelos de veículos, seja através de associações ou aquisições de empresas de capital nacional. Assim, o setor se internacionaliza e se integra à cadeia produtiva em escala mundial." Na China, por exemplo, os principais investidores foram a General Motors (GM), Volks, PSA (Peugeot-Citroen) e Chrysler. O Ipardes (2005) destaca que na Índia, os principais investidores foram as empresas japonesas (Honda e Mitsubishi), a estadunidense GM e Ford, além das europeias Peugeot e Citroen. Tigre et al. (1999) destacam que o principal fator de atração nesses casos foi o mercado potencial, além da maior proximidade dos mercados consumidores potenciais, que permite reduzir os custos logísticos e o risco em relação à alguma medida protecionista.

5 Nesse sentido, “[...] nos últimos anos, as empresas montadoras americanas adquiriram participação no capital de empresas asiáticas e europeias, enquanto as europeias investiram na própria região, e as japonesas e coreanas realizaram operações em novas unidades na Europa e nos EUA. Por outro lado, as empresas também se têm associado para desenvolver novos motores com maior eficiência e menos poluentes. Entre as pesquisas conjuntas, podem ser citadas a da Ford e a PSA (motores diesel), General Motors e Toyota (células de combustível) e Daimler Chrysler e Ford (células de combustível). Esses movimentos de fusão possibilitam maior escala e presença global, o que acaba facilitando a entrada de grandes grupos em mercados potenciais como é o caso brasileiro." (IPARDES, 2010, p.29). 
Tabela 1 - Ranking mundial de produção de veículos automotores por empresa 2009

\begin{tabular}{|c|c|c|c|c|c|c|}
\hline Rank & Grupo & Total & Carros & $\begin{array}{l}\text { Carros } \\
\text { Comer- } \\
\text { ciais Leves } \\
\text { (LCV) }\end{array}$ & $\begin{array}{c}\text { Caminhões } \\
\text { (HCV) }\end{array}$ & $\begin{array}{c}\text { Ônibus } \\
\text { (Heavy } \\
\text { Bus) }\end{array}$ \\
\hline & Total & $60,499,159$ & $51,075,480$ & $7,817,520$ & $1,305,755$ & 300,404 \\
\hline 1 & TOYOTA & $7,234,439$ & $6,148,794$ & 927,206 & 154,361 & 4,078 \\
\hline 2 & G.M. & $6,459,053$ & $4,997,824$ & $1,447,625$ & 7,027 & 6,577 \\
\hline 3 & VOLKSWAGEN & $6,067,208$ & $5,902,583$ & 154,874 & 7,471 & 2,280 \\
\hline 4 & FORD & $4,685,394$ & $2,952,026$ & $1,681,151$ & 52,217 & \\
\hline 5 & HYUNDAI & $4,645,776$ & $4,222,532$ & 324,979 & - & 98,265 \\
\hline 6 & PSA & $3,042,311$ & $2,769,902$ & 272,409 & - & - \\
\hline 7 & HONDA & $3,012,637$ & $2,984,011$ & 28,626 & - & - \\
\hline 8 & NISSAN & $2,744,562$ & $2,381,260$ & 304,502 & 58,800 & - \\
\hline 9 & FIAT & $2,460,222$ & $1,958,021$ & 397,889 & 72,291 & 32,021 \\
\hline 10 & SUZUKI & $2,387,537$ & $2,103,553$ & 283,984 & - & - \\
\hline
\end{tabular}

Fonte: Elaboração própria com base nos dados da Organização Internacional dos Fabricantes de Veículos Automotores (Oica).

O setor automotivo envolve uma participação ampla e significativa de subsetores com ligações para trás e para frente na cadeia produtiva. O automóvel é um bem de consumo durável de alto valor agregado incorporado aos anseios de consumo da sociedade em todas as esferas sociais.

Estima-se que 50\% do total da borracha, 25\% do total de vidro e $15 \%$ do total de aço produzidos no mundo se destinem à indústria automobilística, de acordo com Casotti e Goldenstein (2008).

Esses efeitos de ligação (linkages) ${ }^{6}$ com outras cadeias produtivas e setores econômicos fez com que, em 2007, mais de oito milhões de pessoas estivessem vinculadas diretamente a esse setor de atividade, sendo que, para cada emprego direto, Casotti e Goldenstein (2008) destacam que mais de cinco indiretos são gerados. Além disso, o setor é grande difusor e criador de inovações. Nesse sentido, observa-se que:

6 Porsse (2002) explica que na abordagem tradicionalmente utilizada para identificar, de forma sintética, o encadeamento entre setores envolve o cálculo de índices de ligações para frente (forward) e para trás (backward). Grosso modo, o índice de ligação para frente mostra quanto determinado setor é demandado por todos os setores, enquanto o índice de ligação para trás mostra quanto um determinado setor demanda dos demais setores. Em termos formais, Porsse (2002, p.13) demonstra que o índice de ligação para frente ( $\beta i$ ) expressa o aumento na produção do i-ésimo setor em face de um aumento unitário na demanda final de cada um dos setores, simultaneamente. Já o índice de ligação para trás $(\beta j)$ expressa o aumento total na produção de todos os setores em face de um aumento unitário na demanda final do j-ésimo setor, ou seja, tal índice consiste na soma dos efeitos gerados em cada um dos setores, quando há um choque unitário no j-ésimo setor. 
Além da importância na economia, a indústria automobilística tem sido precursora no desenvolvimento de novas tecnologias e, mais notadamente, em novos modelos de gestão fabril. No último século, ela foi o berço das principais mudanças ocorridas no processo produtivo de toda a cadeia industrial, fundando o que, hoje, conhecemos como Indústria Moderna. (CASOTTI; GOLDENSTEIN, 2008, p.149).

A relevância da indústria automobilística tem sido também acompanhada na referência em padrões de gestão empresarial e de produção. Fordismo e Toyotismo são termos que expressam sistemas de produção que marcaram época e que alcançaram significativa difusão nas mais diversas atividades produtivas, lhes cabendo papel relevante na economia contemporânea. ${ }^{7}$

Diversos estudos apontam que a estrutura produtiva e as respectivas participações setoriais no produto e no emprego são relevantes na determinação dos ganhos de produtividade e consequentemente na determinação da riqueza de uma sociedade ao longo do tempo.

Como exemplo da importância da indústria automotiva e seu elevado grau de encadeamento, Bahia e Domingues (2010) apresentam os multiplicadores simples de produção para o setor. ${ }^{8}$ Para a atividade de caminhões e automóveis tem-se um maior efeito multiplicador na economia (2,47 e 2,23, respectivamente), preponderando os efeitos indiretos, o que indica uma repercussão importante nos demais setores econômicos. As atividades de peças e acessórios representam um elemento de insumo significativo na cadeia produtiva do setor, com um componente direto do multiplicador relativamente superior a automóveis e caminhões. ${ }^{9}$

Observa-se que a produção de um veículo envolve desde insumos básicos até produtos mais complexos da indústria de eletrônicos, além dos serviços relacionados à venda e manutenção. Por sua vez, esses são importantes por se tratar de um bem de consumo durável.

A indústria automobilística apresenta algumas características relevantes como, por exemplo, os ganhos de economias de escala e de aglomeração e o nível de intensidade tecnológica que envolve a produção de um veículo, o que

$7 \quad$ Para uma análise da estrutura de inovações na indústria automobilística brasileira, veja Bahia e Domingues (2010).

8 Rodrigues et al. (2007) destacam que os multiplicadores de produção complementam a análise da importância de determinado setor na economia, na medida em que são instrumentos úteis empregados na verificação de impactos sobre determinado sistema econômico resultante de choques nos elementos exógenos, a curto ou longo prazo. O emprego dos multiplicadores permite verificar, por exemplo, os efeitos de políticas públicas sobre a produção total da economia ou sobre outras variáveis como o nível de emprego e a renda. Os multiplicadores de produção permitem determinar o impacto de variações na demanda final sobre o volume de produção. Quando maior o multiplicador apresentado maior o impacto sobre as demandas finais em relação ao volume de produção da atividade.

9 De acordo com Bahia e Domingues (2010), isso indica a existência de um componente intrassetorial mais intenso dos efeitos multiplicadores e destaca um componente de inter-relações produtivas entre as firmas de peças e acessórios. 
demanda um volume de capital inicial elevado para uma empresa acessar o mercado, resultando em significativas barreiras à entrada. ${ }^{10}$

A forte presença de economias de escala e de aglomeração na produção de veículos também traz consequências para a tomada de decisão relativa à localização da empresa, bem como seus sistemistas. Esses dois fatores em conjunto tendem a estimular um setor caracterizado por uma concentração de grandes empresas, aglomeradas em algumas regiões geográficas não muito dispersas. Ou seja, é uma característica desse mercado a concentração industrial e a aglomeração produtiva.

Dessa forma, uma vez instalada uma montadora em determinada região, tende a ser natural o surgimento de oportunidades atrativas ao longo do processo produtivo. Essas oportunidades são ampliadas através de um sistema de produção no qual a empresa que coordena o processo - geralmente a montadora, proprietária da marca do veículo, terceiriza parte significativa da produção de peças e acessórios, o que se tornou ainda mais comum nas unidades produtivas a partir dos anos 1990.

Na próxima seção é feita uma análise do cenário internacional e o desempenho do setor automotivo no Brasil de 2000 a 2009.

\section{A Indústria Automotiva: Produção Doméstica e Cenário Internacional}

A indústria automotiva segue apresentando elevadas taxas de crescimento com relação ao nível de produção, principalmente nos países em desenvolvimento. A inserção dos países asiáticos, com destaque para China e Índia, que representam aproximadamente $37 \%$ da população mundial e têm alcançado elevadas taxas de crescimento econômico, de acordo com os dados disponibilizados pelo Banco Mundial (2007), é um fenômeno que merece atenção com relação aos efeitos de expansão do mercado automobilístico. A China, em especial, tem mantido uma taxa média de crescimento econômico próximo a 10\% a.a., ao longo das três últimas décadas.

A dinâmica do crescimento econômico da China e Índia teve grande reflexos sobre o setor automotivo. Na Tabela 2 é apresentado o crescimento (em \%) da produção de veículos por país, tendo como base o ano de 2000. O crescimento de 2000 a 2009 da produção de veículos observada tanto na China quanto na Índia fica muito acima da média dos demais países, sendo esse um desempenho condizente com a expansão econômica observada em ambos. Se considerada a taxa de crescimento econômico no mesmo período - 1997 a 2009 -, a China cresceu em média 9,02\% a.a, enquanto a Índia obteve um crescimento médio de 6,08\% a.a. (BANCO MUNDIAL, 2010).

10 Para o conceito de economias de escala e aglomeração, ver Polèse (1998). Para o conceito de barreiras à entrada, ver Fagundes e Ponde (2001). 


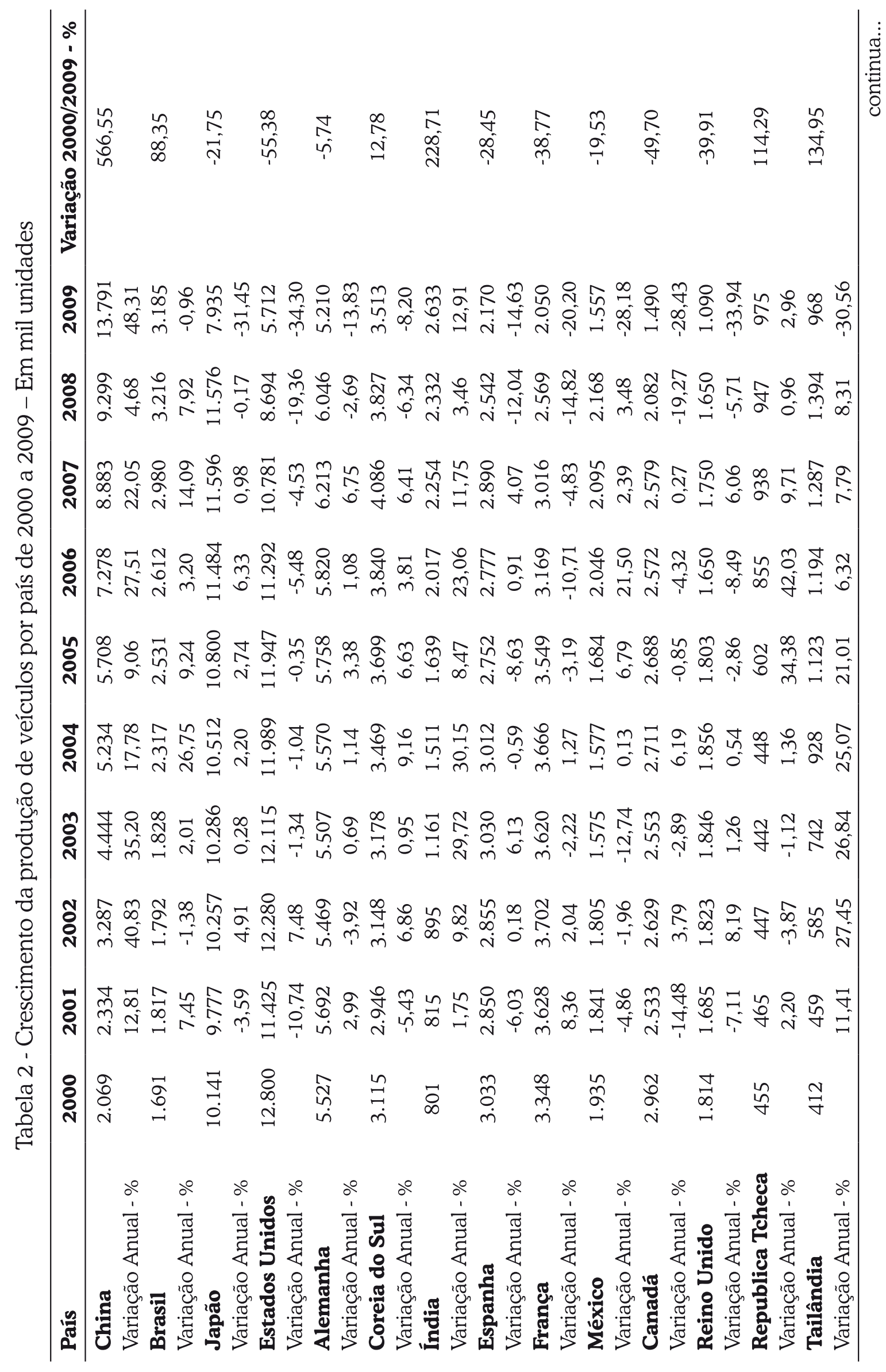

GABRIEL, L. F. A Indústria Automobilística no Brasil e a Demanda de Veículos no Período... 


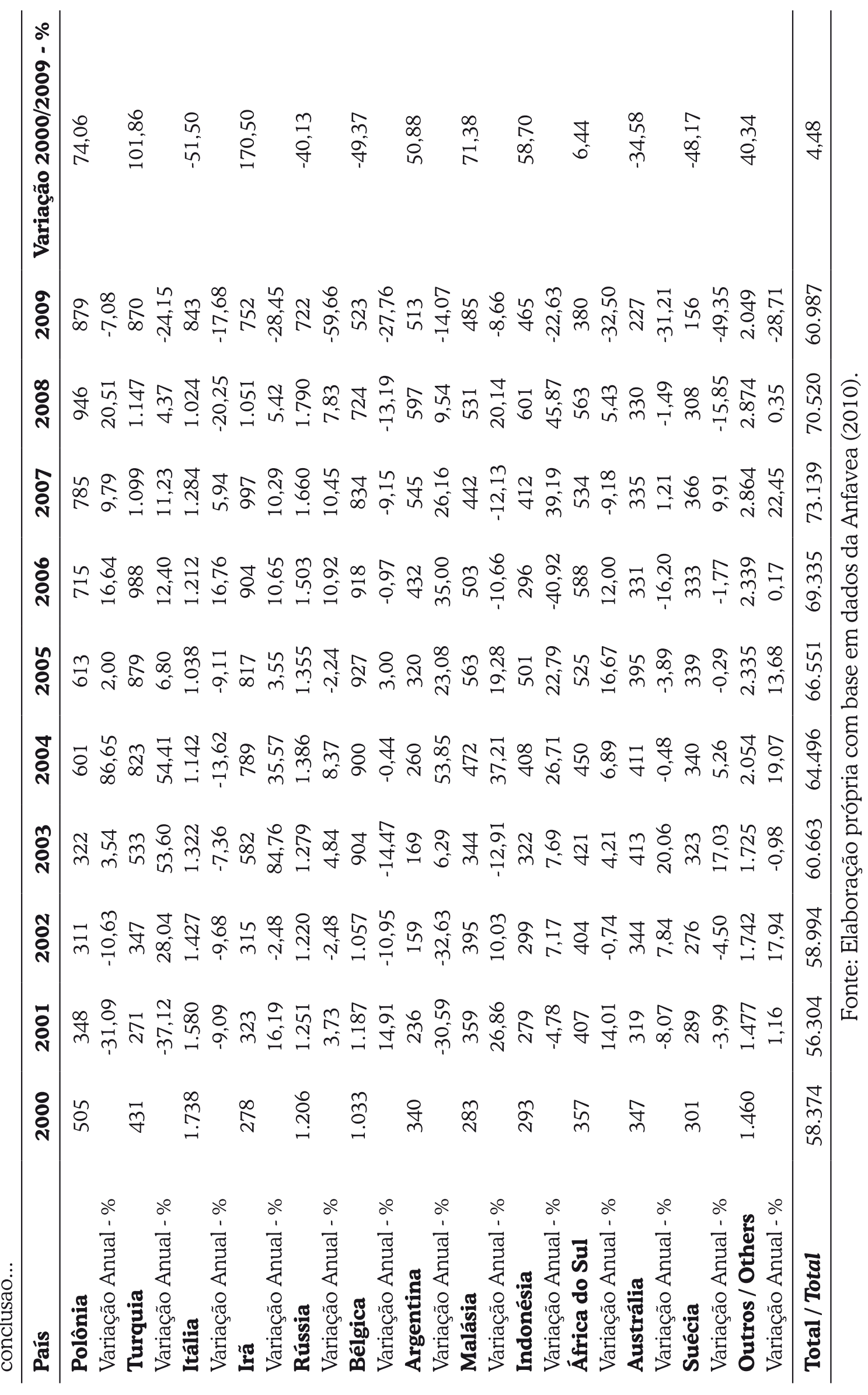


Ainda de acordo com os dados do Banco Mundial (2010), a China apresentou uma queda significativa do número de pessoas vivendo abaixo da linha de pobreza. ${ }^{11}$ Foram aproximadamente 250 milhões de pessoas entre 1991 e 2004 , sendo o dobro, se considerado o período desde 1981. Ainda assim, em 2004, havia 130 milhões de chineses nessa condição. A Índia ainda mantinha em 2004, aproximadamente 367 milhões de pessoas abaixo da linha de pobreza. Consideradas as devidas proporções, Brasil e Rússia, assim como China e Índia, todavia, mantêm um número significativo de demanda reprimida por automóveis.

Esses dados demonstram que ainda existe uma demanda potencial representativa nesses países. Caso eles mantenham taxas elevadas de crescimento econômico nos próximos anos, provavelmente serão responsáveis por uma expansão expressiva da produção e consumo de veículos.

A Tabela 2 permite sugerir ainda que o novo padrão internacional de concorrência sofrerá cada vez mais influência de países como China e Índia. ${ }^{12}$ Esses dois países, que crescerem acima da média internacional, atraíram, recentemente, um grande nível de investimentos e se configuram hoje como importantes mercados da indústria automotiva.

De acordo com Casotti e Goldenstein (2008), a dimensão internacional que seus produtos podem alcançar e a velocidade com que esse processo vem se dinamizando recentemente têm influenciado enormemente os padrões de concorrência mundial e nacional. Segundo a Anfavea (2010), a alta carga tributária no Brasil, o preço das matérias-primas e problemas nos processos de produção fazem com que o custo de fabricação de carros nacionais seja, em média, 30\% superior em comparação com outros países. ${ }^{13}$

A indústria automotiva no Brasil apresentou um crescimento bastante significativo no período recente. Ao considerar a produção de veículos desde 1957, observa-se que desde 2003 o país vem alcançando recordes históricos.

11 Refere-se à linha de pobreza adotada pelo Banco Mundial para comparações internacionais, tendo como referência $\$ 1,08$ dólar internacional per capita dia.

12 O grande destaque em relação à evolução na produção mundial de veículos por país é o aumento fenomenal da participação chinesa na economia mundial, em relação aos demais países, como pôde ser observado na Tabela 2. Essa participação passou de 3,54\%, em 2000, para 22,61\%, em 2009. Em relação a maior economia do mundo, a qual participou com cerca de $25 \%$ do PIB Mundial em 1998 pelo cálculo de participação relativa do PIB pela Paridade do Poder de Compra (PPC) em 2010, observou-se uma grande perda de sua participação na produção mundial ao longo da primeira década do século XXI. Essa queda foi de mais de $55 \%$ no período compreendido entre 2000 e 2009. Essas informações sugerem que o declínio relativo da economia norteamericana está sendo moldado pela dinâmica econômica de economias emergentes, principalmente devido à China.

13 De acordo com a Fenabrave/Anfavea (2011), entre os fornecedores externos de automóveis, os argentinos são hoje os mais representativos. No primeiro trimestre de 2011, o Brasil importou US\$ 2,4 bilhões em veículos de passageiros. Os argentinos ficaram com uma fatia de $36,2 \%$ desse valor. A Coreia do Sul é a segunda maior fornecedora externa, com $26,3 \%$ do total. O México aparece em terceiro lugar, com $13,9 \%$. Já a China apareceu com 4,5\%, com exportações de US\$ 38,9 milhões em carros ao Brasil no primeiro trimestre de 2011. 
A partir do Gráfico 1, é possível perceber quatro períodos que se destacam com relação ao aumento da produção de veículos (INSTITUTO EUVALDO LODI - IEL-PR, 2010). O primeiro, entre 1957 e 1961, marca a instalação da indústria automobilística no país e é acompanhado de elevadas taxas de crescimento econômico, com uma média de 8,8\% a.a. O segundo período, entre 1968 e 1980, abrange um momento em que o Brasil alcançou uma das maiores médias históricas de crescimento econômico por mais de uma década, de aproximadamente $8,9 \%$ a.a, marcado pela forte expansão da produção da indústria automotiva no país, tendo como principal foco o mercado interno. $\mathrm{O}$ terceiro período refere-se ao início da década de 1990 até meados de 1997, abrangendo a abertura de mercado, tendo forte estímulo por parte das oportunidades advindas do mercado externo, em função de uma dinâmica de internacionalização da produção. Já o período mais recente, com início em 2004 e que prossegue até meados de 2008 é caracterizado pelo aquecimento do mercado externo e doméstico, concomitantemente.

Gráfico 1 - Produção de autoveículos por categoria no Brasil - 1957 a 2009

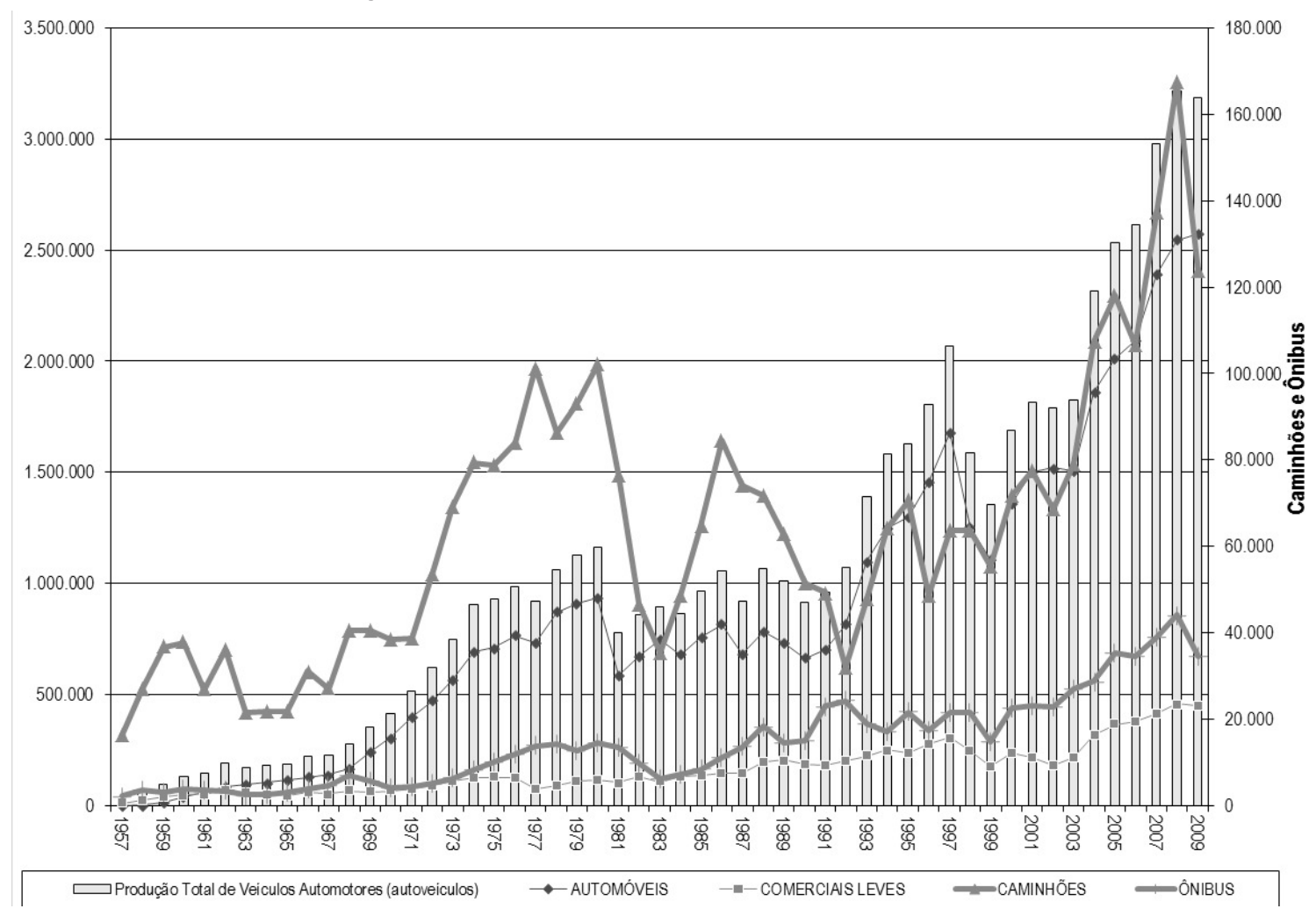

Fonte: Elaboração própria com base em dados da Anfavea (2010).

Nota: Caminhões e Ônibus estão no eixo secundário do gráfico (escala de 0 a 180.000 unidades produzidas).

A retomada do setor automotivo brasileiro, ancorada no mercado interno, teve início em 2004. De acordo com dados do Instituto de Pesquisa Econômica Aplicada - Ipea (2010) e do Banco Nacional do Desenvolvimento - BNDES (2009), 
o principal motor do processo foi o crescimento sustentado da economia. Além disso, a queda da taxa de juros Selic e as mudanças institucionais que afetaram a concessão de crédito impulsionaram a expansão do mercado interno.

De acordo com o BNDES (2009), as principais montadoras voltaram a apresentar resultados positivos, surgindo os primeiros indícios de esgotamento da capacidade ociosa já em 2007.

Os dados das Tabelas 2 e 3 permitem sugerir que o mercado nacional passou a assumir maior importância entre as montadoras internacionais, tendo em vista a estagnação ou redução da participação internacional dos mercados maduros, como Estados Unidos, União Europeia e Japão.

De acordo com dados do BNDES (2009), além dos investimentos em modernização de processos produtivos, em reestilização de modelos e em desenvolvimento de novos veículos, todas as montadoras têm realizado investimentos também em aumento de capacidade produtiva.

Por meio da Tabela 3, pode-se observar que a produção de automóveis, comerciais leves, caminhões e ônibus passou de 1,35 milhão, em 1999, para um máximo de 3,21 milhões, em 2008, e 3,18 milhões em 2009. As vendas internas saltaram de 1,256 milhão de veículos, em 1999, para 3,141 milhões em 2009. 


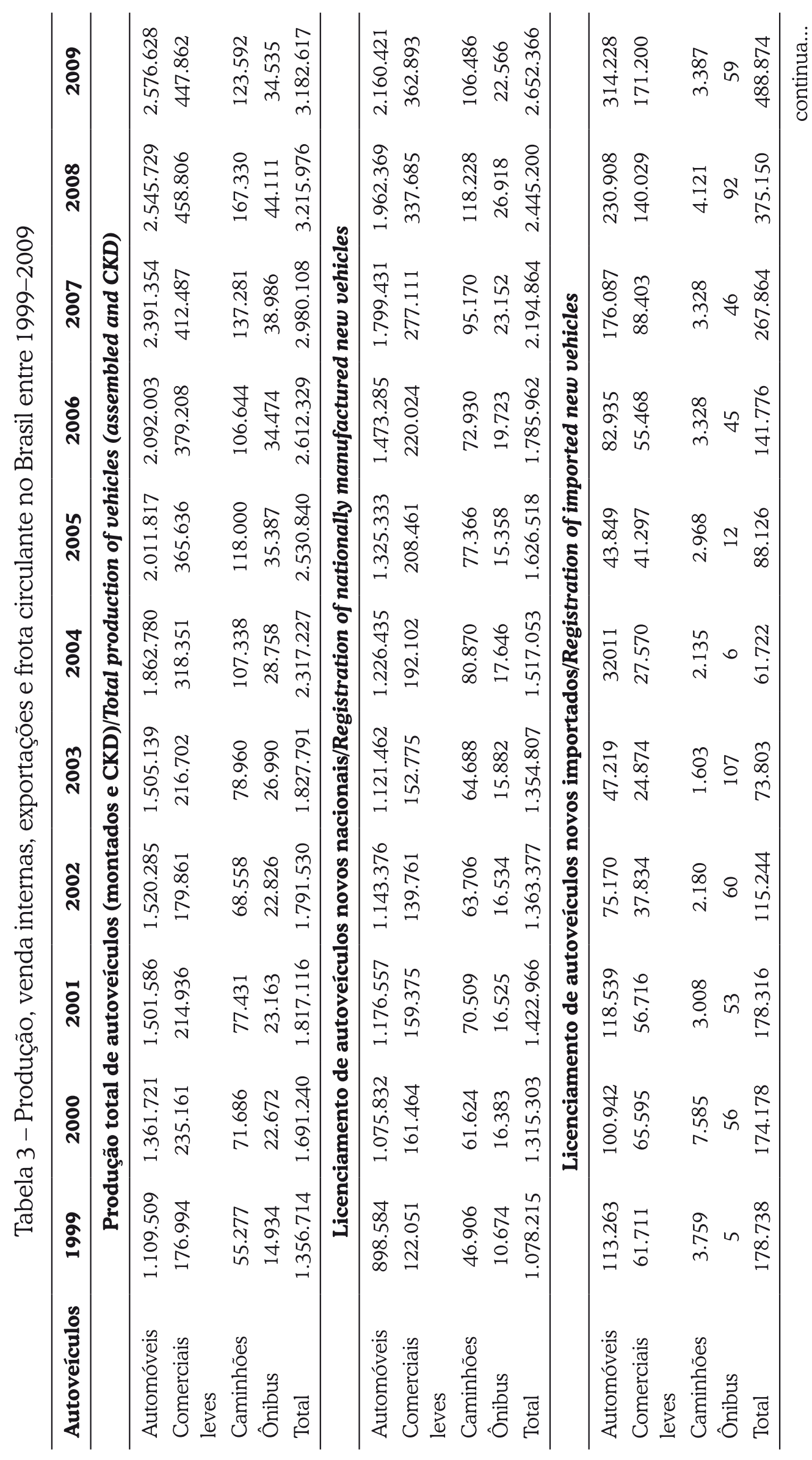




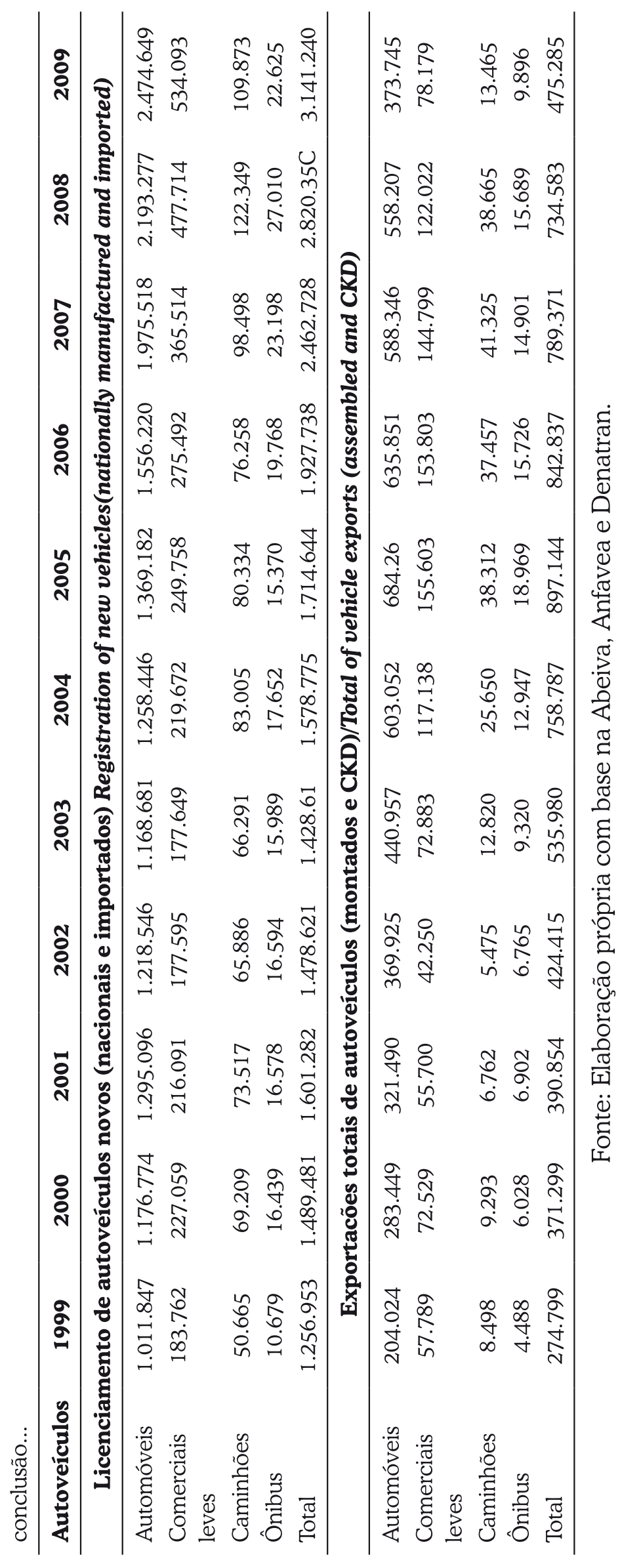


A partir de dados do BNDES (2009) e da Associação Nacional dos Fabricantes de Veículos Automotores - Anfavea (2010), pode-se perceber que o mercado interno ingressou em um ritmo acelerado de crescimento no ano de 2008.

As projeções iniciais previam uma expansão do mercado superior a $20 \%$, quando diversas montadoras adotaram um terceiro turno de produção.

O crescimento verificado no período de 2008 (em relação a 2007) foi de $7,91 \%$ em termos de produção total de autoveículos. A produção nos primeiros nove meses do ano de 2008 já superava em $20 \%$ a verificada em 2007. Entre janeiro e setembro de 2007, a produção foi de 2.186.018; já no mesmo período de 2008, observou-se uma produção de 2.624.357.

De acordo com dados da Associação Nacional das Empresas Financeiras das Montadoras (Anef), apenas $28 \%$ das vendas de veículos no Brasil são efetivadas com pagamentos à vista. Com essa grande dependência do mercado de crédito, ${ }^{14}$ a contração de crédito verificada a partir de outubro de 2008 significou uma mudança súbita da tendência de crescimento do setor. A partir dos dados analisados da Anfavea, ocorreu uma queda de $69,52 \%$ na produção entre julho e dezembro de 2008.

A produção média de veículos mensal em 2008 foi de 267.998 veículos. Contudo, em dezembro, a produção caiu para 97.048. O impacto da crise internacional se fez sentir em outubro de 2008 , com queda de $6 \%$ da comercialização de autoveículos em relação ao ano anterior, sendo mais acentuado em novembro e dezembro, quando a comercialização de autoveículos caiu 23,45\% e 19,7\%, respectivamente, em relação ao mesmo período.

De acordo com o BNDES (2009), as empresas da indústria automobilística colocaram em prática planos de contingência a partir de novembro de 2008. Entre as ações adotas nesses planos destacaram-se as reduções de turnos de trabalho e férias coletivas tanto nas montadoras quanto no setor de autopeças.

Em dezembro de 2008, o governo anunciou a redução do IPI. Essa medida foi fundamental para estancar a queda das vendas nos meses subsequentes de 2009, quando, de acordo com o BNDES (2009), as montadoras e empresas do setor de autopeças iniciaram a reconvocação dos funcionários licenciados.

Apesar dessa reversão do setor em 2008, pode-se verificar, por meio da Tabela 3, que este foi o período de maior produção da indústria automobilística, com um total de 3,215 milhões de veículos produzidos.

14 As vendas no Brasil são fortemente dependentes da concessão de crédito, fundamentalmente de $\mathrm{CDC}$ e de leasing e $\mathrm{CDC}$. Além disso, no caso específico de caminhões e ônibus, a Finame financia mais de $50 \%$ do valor das vendas no mercado interno. Para o caso de autoveículos, é realizado um estudo econométrico na seção 4 para se analisar os principais fatores que vieram a influenciar a demanda no Brasil no período 2000-2010. 
Além disso, foram emplacados cerca de 4,8 milhões de veículos e licenciados cerca de 2,9 milhões de autoveículos, conforme a Tabela 3.

Em janeiro de 2009, a produção sofreu uma queda de $27,33 \%$ em relação ao mesmo período de 2008. Contudo, na esteira da crise no setor do segundo semestre de 2008, a produção de 184.704 veículos automotores em janeiro de 2009 significou um aumento de 90,32\% em relação a dezembro de 2008.

Os estímulos para o setor significaram uma produção de 3,182 milhões de veículos automotores em 2009. Esse nível de produção resultou em uma queda de $1,04 \%$ em relação ao ano de 2008.

\section{Estimativa de Demanda de Veículos Automotores no Brasil de Junho de 2000 a Outubro de 2010: Algumas Evidências a partir de uma Abordagem Econométrica}

Fauth, Morais e Clezar (2009) destacam que poucos são os estudos que têm se aprofundado na análise da demanda de veículos no mercado interno brasileiro. De forma usual, esses estudos se dividem na literatura do tema entre modelos agregados, os quais relacionam a quantidade total de veículos vendidos com variáveis explicativas, como preço e nível de renda, ou ainda modelos desagregados, em que se considera a demanda por produtos diferenciados (com marcas), explicado pela função de utilidade de cada indivíduo no mercado.

Nesta seção, testa-se um modelo de demanda agregada, com base na venda do mercado interno de veículos automotores, o nível de salário mínimo real (como proxy do nível de renda), o preço dos veículos, as taxas médias de juros mensais das operações de financiamento de veículos automotores, o volume de crédito destinado aos financiamentos de veículos, o crédito total na economia e a relação crédito PIB (nesses dois últimos casos, operações pós-fixadas, exclusiva para operações de aquisições de veículos).

Na Tabela 4, tem-se a descrição das variáveis do modelo de demanda a ser testado. 


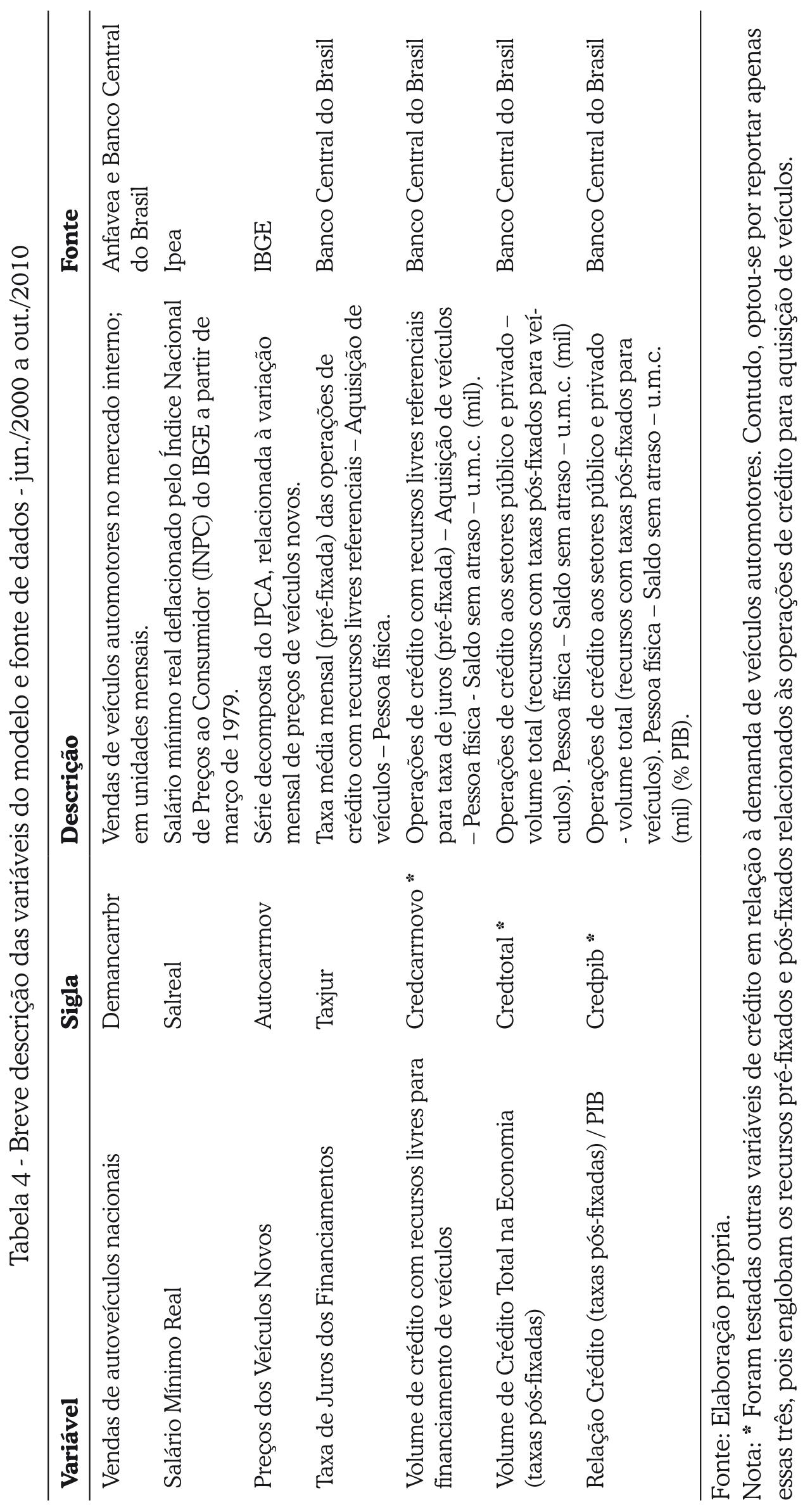


A equação de demanda linear em termos formais é descrita da seguinte maneira:

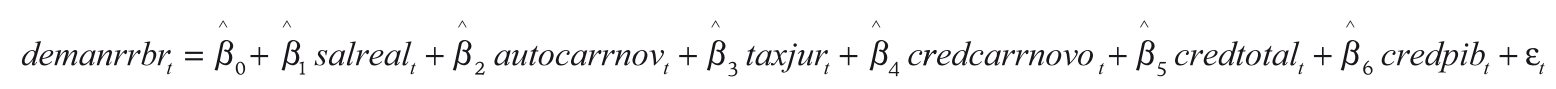
em que os $\beta$ (betas) representam os parâmetros a serem estimados.

Para que a inferência estatística a respeito dos parâmetros esteja robusta, é fundamental que as séries temporais consideradas sejam estacionárias, ou de forma similar, que não possuam raiz unitária.

De acordo com Enders (2004), uma série temporal é estacionária se as seguintes propriedades forem respeitadas: a média e a variância devem ser constantes ao longo do tempo e a covariância entre dois períodos de tempo deve depender apenas da defasagem entre os períodos de tempo, independentemente do tempo específico considerado.

A desconsideração da questão da estacionariedade pode levar a resultados enganosos conduzindo ao problema da regressão espúria. Regressões espúrias costumam gerar resultados aparentemente satisfatórios, mas que ocorrem apenas devido às séries apresentarem tendências semelhantes e não a verdadeira relação entre elas. ${ }^{15}$

Neste artigo, utilizou-se o teste $\mathrm{ADF}$ (Augmented Dickey-Fuller) para se verificar a estacionariedade das séries. Nesse teste, as hipóteses nula $\left(\mathrm{H}_{\mathrm{o}}\right)$ e alternativa $\left(\mathrm{H}_{1}\right)$ são as seguintes:

$\mathrm{H}_{\mathrm{o}}$ : a série temporal apresenta raiz unitária.

$\mathrm{H}_{1}$ : a série temporal não apresenta raiz unitária.

Dessa forma, caso o resultado do teste indique a não rejeição da hipótese nula, admite-se que a série temporal é não estacionária. Caso contrário, por sua vez, se o resultado do teste indicar a rejeição da hipótese nula e, consequentemente, a aceitação da hipótese alternativa, sugere-se ausência de raiz unitária e a consequente estacionariedade da série temporal.

Os resultados dos testes $\mathrm{ADF}$ aplicados a todas as séries da equação de demanda são apresentados na Tabela 5.

15 Gujarati (2000) demonstra que equações que apresentam um coeficiente de determinação R2 elevado, associado a resíduos altamente correlacionados indicados por um baixo valor da estatística "d" de Durbin-Watson, apontam para possibilidade de regressão espúria. Nesse caso, o valor de R2 bem como os testes "t" e " $F$ " são inválidos. Assim, quando é constatado que uma série temporal é não estacionária, ou ainda, que esta possui raiz unitária, recomenda-se que esta seja diferenciada até que se alcance a estacionariedade. Trabalhar com a primeira diferença, ou até mesmo com diferenças de maior ordem, caso seja necessário, torna possível a estimação de uma regressão válida e consistente. O número de vezes que a série precisa ser diferenciada para tornar-se estacionária corresponde à ordem de integração da série. Uma série estacionária em nível é integrada de ordem zero e representada por I(0), enquanto uma série estacionária apenas em primeira diferença é dita integrada de ordem um, ou I(1), e assim por diante. Para tentar detectar a existência ou não de raiz unitária nas séries temporais em análise, recorrer-se-á aos testes Dickey-Fuller aumentado (ADF). 
Tabela 5 - Testes de raiz unitária pelo teste Augmented Dickey-Fuller (ADF)

\begin{tabular}{lccccccc}
\hline Sigla & Intercepto & Tendência & ADF & Lag & $\mathbf{1 \%}$ & $\mathbf{5 \%}$ & $\mathbf{1 0 \%}$ \\
\hline Demancarrbr & Sim & Sim & $-2,68^{*}$ & 12 & $-4,04$ & $-3,45$ & $-3,15$ \\
Salreal & Sim & Sim & $-2,03^{*}$ & 12 & $-4,04$ & $-3,45$ & $-3,15$ \\
Autocarrnov & Não & Não & $-6,40$ & 0 & $-4,03$ & $-3,44$ & $-3,14$ \\
Taxjur & Não & Não & $-3,38^{*}$ & 12 & $-4,04$ & $-3,45$ & $-3,15$ \\
Credcarrnovo & Não & Sim & $-1,99^{*}$ & 3 & $-4,03$ & $-3,44$ & $-3,14$ \\
Credtotal & Não & Não & $-2,15^{*}$ & 0 & $-4,03$ & $-3,44$ & $-3,14$ \\
Credpib & Não & Sim & $-0,98^{*}$ & 0 & $-4,03$ & $-3,44$ & $-3,44$ \\
\hline
\end{tabular}

Fonte: Elaboração própria.

Nota: O número ótimo de lag foi definido pelo critério de Akaike. * A série é não estacionária em nível para um nível de significância de 5\%.

Na Tabela 6 são apresentadas as ordem de integração das séries.

Tabela 6 - Ordem de integração das séries e nova nomenclatura da variável estacionária

\begin{tabular}{lcc}
\hline Sigla & Ordem de integração das séries & Variável estacionária \\
\hline Demancarrbr & $\mathrm{I}(1)$ & ddemancarrbr \\
Salreal & $\mathrm{I}(1)$ & ddsalreal \\
Autocarrnov & $\mathrm{I}(0)$ & $=$ \\
Taxjur & $\mathrm{I}(1)$ & dtaxjur \\
Credcarrnovo & $\mathrm{I}(2)$ & ddcredcarrnovo \\
Credtotal & $\mathrm{I}(1)$ & dcredtotal \\
Credpib & $\mathrm{I}(1)$ & dcredpib \\
\hline
\end{tabular}

Fonte: Elaboração própria com base nos resultados nos testes de estacionariedade das séries. Nota: Um "d" adicional na coluna de "variável estacionária" significa um processo em primeira diferenciação. Dois "d" significam que a variável está em segunda diferença.

A estimava da equação de demanda utilizando-se mínimos quadros ordinários (M.Q.O.) é apresentada na Tabela 7.

Tabela 7 - Equação de demanda doméstica de veículos - Jun./2000 a Out./2010

\begin{tabular}{lcccc}
\hline \multicolumn{5}{c}{$\begin{array}{c}\text { Dependent Variable: DDEMANCARRBR } \\
\text { Method: Least Squares }\end{array}$} \\
\hline Variable & Coefficient & Std. Error & $t$-Statistic & Prob. \\
C & 2076.785 & 1914.296 & 1.084882 & 0.2802 \\
DDSALREAL & -178.9454 & 96.63565 & -1.851754 & 0.0666 \\
AUTOCARRNOV & -6960.251 & 2574.470 & -2.703566 & 0.0079 \\
DTAXJUR & -3118.698 & 1141.537 & -2.732017 & 0.0073 \\
DDCREDCARRNOVO & 0.004436 & 0.002475 & 1.792266 & 0.0757 \\
DCREDTOTAL & -0.006201 & 0.014606 & -0.424548 & 0.6720 \\
\hline
\end{tabular}

continua... 


\section{Dependent Variable: DDEMANCARRBR}

Method: Least Squares

\begin{tabular}{lcccc}
\hline Variable & Coefficient & Std. Error & t-Statistic & Prob. \\
DCREDPIB & -2861.873 & 3360.740 & -0.851560 & 0.3962 \\
R-squared & 0.179273 & Mean dependent var & 1088.715 \\
Adjusted R-squared & 0.136822 & & S.D. dependent var & 21427.65 \\
\hline
\end{tabular}

Fonte: Elaboração própria a partir da saída resumida do Eviews.

Nota: A matriz de correlação para essas variáveis apresentou valores muito baixos para todos os pares de variáveis, sugerindo que não há um problema de multicolinearidade na regressão estimada.

As variáveis estatisticamente significativas (para um intervalo de confiança 90\%) para explicar a demanda de autoveículos no mercado doméstico foram o preço dos bens (autocarrnov), a taxa de juros dos financiamentos utilizada (dtaxjur) e o volume de crédito utilizado em operações de crédito com recursos livres referenciais para taxa de juros (pré-fixada, variável "ddcredcarrnovo"). ${ }^{16}$

Esses resultados sugerem que a demanda de veículos automotores é influenciada em larga medida pelo custo e pelo volume de crédito relacionado a essas operações no mercado doméstico no período analisado. Nesse sentido, o consumidor do mercado nacional escolhe a aquisição do bem com as prestações mensais que "cabem em seu bolso", dado que essas variáveis refletirão, em último caso, sobre o custo do financiamento.

O preço do bem também é significativo estatisticamente para se explicar a demanda doméstica (com intervalo de confiança de 90\%). Com isso, políticas que visem reduzir o preço final do bem em questão podem representar um novo estímulo sobre a demanda. A redução do IPI durante o período de contágio da crise internacional recente é um fato estilizado para o caso, dado que, na série apresentada na seção anterior, o impacto da redução do preço dos bens sobre o volume de veículos licenciados foi bastante significativo, elevando o nível de vendas entre o fim do segundo semestre de 2008 e início de 2009 (ver seção 3).

O sinal esperado para a variável de salário real não foi o inicialmente previsto, apesar de ser significativa estatisticamente, dado que a relação de aumento de renda (medido aqui pela variável "salreal") não teve o impacto positivo esperado sobre a demanda de veículos. Entretanto, isso não significa inferir que o nível de renda não seja importante para o consumo dos bens em estudo, como se pode verificar para períodos mais longos com as variáveis de nível de renda per capita e o volume de vendas e produção em estudos do CPS/FGV. Além disso, fazendo-se uma análise ex post dos resultados pode-se constatar que a variável utilizada não estratifica as mudanças da estrutura de classes sociais verificadas na seção anterior a partir dos dados do CPS/FGV.

16 A variável "salreal" também é significativa estatisticamente. Contudo, deixaremos os comentários a seu respeito para os próximos parágrafos.

GABRIEL, L. F. A Indústria Automobilística no Brasil e a Demanda de Veículos no Período... 
Para se avaliar a qualidade dos resultados, realizou-se o teste Breusch-Godfrey Serial Correlation - LM (Lagrangian Multiplier) Test a fim de se verificar a existência de autocorrelação serial e não se rejeitou a hipótese nula do teste (a qual postula que não há autocorrelação serial até a defasagem de ordem 1). Além disso, utilizouse o teste de heterocedasticidade de White e não se rejeitou a hipótese nula de não existir heterocedasticidade. O nível de significância dos testes foi de $5 \% .{ }^{17}$

O comportamento das variáveis é explicado exclusivamente pelos valores presentes e passados das "n" outras variáveis do modelo, e é fundamental a escolha correta do número de defasagens a ser adotado para se aplicar testes do tipo VAR, VEC, Causalidade de Granger e Decomposição da Variância. ${ }^{18}$

Para a definição do número "p" de defasagens para o teste de causalidade, será utilizado o critério de Akaike Information Criterion (AIC). De acordo com essa metodologia, o número ótimo de defasagens é $10 .{ }^{19}$

Para se analisar a relação de causalidade entre as variáveis do modelo, utilizou-se o teste de Causalidade Granger. De acordo com Enders (2004), esse teste é usado para verificar se os lags de uma variável entram na equação de outra. Além disso, o teste de causalidade Granger visa examinar a questão da causalidade entre duas variáveis para se investigar a hipótese de que uma variável atribua importância para outra variável. Nesse caso, é pertinente a sua utilização para análise da demanda doméstica de autoveículos no Brasil. ${ }^{20}$

17 O valor do teste de Heterocedasticidade de White (opção no cross terms) é de 14,36 e o valor crítico de distribuição Chi Quadrado é 21,02, ao nível de significância de 5\%. Portanto, não se rejeita a hipótese nula de não existir heterocedasticidade. Dessa forma, somente utilizar-se-ia o método de correção da heterocedasticidade (como mínimos quadrados ponderados) se o valor dado pelo teste de White fosse maior do que o valor Chi Quadrado tabelado ao nível de significância definido. A hipótese nula do teste LM é que não há autocorrelação serial até a defasagem "p". No caso foi escolhida uma defasagem apenas $(p=1)$. O resultado que o Eviews fornece é de 7,38 como estatística do teste "Breusch-Godfrey LM test", o qual é menor do que valor Chi quadrado tabela de distribuição Chi quadrado. Somente se o "Breusch-Godfrey LM Test Statistic" de 7,38 excedesse o valor crítico de Chi Quadrado, é que se poderia rejeitar a hipótese de não existir autocorrelação serial em um nível de $5 \%$ de significância. Além disso, a probabilidade de " 0,000879 " representa a probabilidade de que estaria incorreto se fosse rejeitada a hipótese nula de até o nível de defasagem 1 a um intervalo de confiança de $95 \%$.

18 Não será apresentado aqui uma modelo VAR ou VEC por ir muito além do escopo do artigo. Contudo, utilizaremos a metodologia de decomposição da variância para demonstrar como a demanda de veículos (demancarrnovbr) é, grosso modo, afetado pelas outras variáveis do modelo de demanda utilizado. A decomposição da variância é outra forma para descrever a dinâmica de um determinado sistema. Por esse método, torna-se possível identificar a proporção da variação total de uma variável devida a cada choque individual em " $\mathrm{k}$ " variáveis componentes do modelo. Portanto, a decomposição da variância fornece informação sobre a importância relativa de cada "inovação" ("mudança" ou "choque" em um sistema de "impulso" "resposta") sobre as variáveis do sistema.

19 Cabe destacar a opção pela realização do teste com mais defasagens em função do critério de Davidson e MacKinnon (1993) de se utilizar mais (ao invés de menos) defasagens dada a sensibilidade do teste de Granger.

20 A ideia por trás deste teste, ao se verificar se uma determinada variável x causa y, é saber quanto se pode explicar dos valores correntes desta última tendo por base seus valores passados e se tal explicação aumenta a sua eficácia ao acrescentar valores defasados da variável x. A hipótese nula do teste é que a variável $x$ não causa, no sentido Granger, a variável y. Isso significa que ao rejeitar a hipótese nula indicamos causalidade entre as variáveis. 
Tabela 8 - Teste de Causalidade de Granger - Jun./2000 a Out./2010

\begin{tabular}{|c|c|c|c|}
\hline \multicolumn{4}{|l|}{ Pairwise Granger Causality Tests } \\
\hline Null Hypothesis: & Obs & F-Statistic & Probability \\
\hline DDSALREAL does not Granger Cause DDEMANCARRBR & 121 & 1.83412 & 0.16436 \\
\hline DDEMANCARRBR does not Granger Cause DDSALREAL & & 0.47406 & 0.62367 \\
\hline $\begin{array}{l}\text { AUTOCARRNOV does not Granger Cause } \\
\text { DDEMANCARRBR }\end{array}$ & 122 & 3.40313 & 0.03660 \\
\hline $\begin{array}{l}\text { DDEMANCARRBR does not Granger Cause } \\
\text { AUTOCARRNOV }\end{array}$ & & 10.6375 & 5.7E-05 \\
\hline $\begin{array}{l}\text { DTAXJUR does not Granger Cause } \\
\text { DDEMANCARRBR }\end{array}$ & 122 & 3.54085 & 0.03213 \\
\hline DDEMANCARRBR does not Granger Cause DTAXJUR & & 1.37138 & 0.25780 \\
\hline $\begin{array}{l}\text { DDCREDCARRNOVO does not Granger Cause } \\
\text { DDEMANCARRBR }\end{array}$ & 121 & 4.13567 & 0.01841 \\
\hline $\begin{array}{l}\text { DDEMANCARRBR does not Granger Cause } \\
\text { DDCREDCARRNOVO }\end{array}$ & & 6.09332 & 0.00305 \\
\hline $\begin{array}{l}\text { DCREDTOTAL does not Granger Cause } \\
\text { DDEMANCARRBR }\end{array}$ & 122 & 2.27578 & 0.10725 \\
\hline DDEMANCARRBR does not Granger Cause DCREDTOTAL & & 0.75075 & 0.47427 \\
\hline DCREDPIB does not Granger Cause DDEMANCARRBR & 122 & 1.09118 & 0.33921 \\
\hline DDEMANCARRBR does not Granger Cause DCREDPIB & & 0.97059 & 0.38189 \\
\hline AUTOCARRNOV does not Granger Cause DDSALREAL & 121 & 0.32541 & 0.72289 \\
\hline DDSALREAL does not Granger Cause AUTOCARRNOV & & 1.78683 & 0.17207 \\
\hline DTAXJUR does not Granger Cause DDSALREAL & 121 & 0.44431 & 0.64235 \\
\hline DDSALREAL does not Granger Cause DTAXJUR & & 0.63889 & 0.52972 \\
\hline $\begin{array}{l}\text { DDCREDCARRNOVO does not Granger Cause } \\
\text { DDSALREAL }\end{array}$ & 121 & 0.25711 & 0.77372 \\
\hline $\begin{array}{l}\text { DDSALREAL does not Granger Cause } \\
\text { DDCREDCARRNOVO }\end{array}$ & & 0.03135 & 0.96914 \\
\hline DCREDTOTAL does not Granger Cause DDSALREAL & 121 & 0.07397 & 0.92875 \\
\hline DDSALREAL does not Granger Cause DCREDTOTAL & & 0.03045 & 0.97001 \\
\hline DCREDPIB does not Granger Cause DDSALREAL & 121 & 0.37529 & 0.68792 \\
\hline DDSALREAL does not Granger Cause DCREDPIB & & 2.87877 & 0.06023 \\
\hline DTAXJUR does not Granger Cause AUTOCARRNOV & 122 & 3.33155 & 0.03916 \\
\hline AUTOCARRNOV does not Granger Cause DTAXJUR & & 1.08256 & 0.34210 \\
\hline $\begin{array}{l}\text { DDCREDCARRNOVO does not Granger Cause } \\
\text { CARRNOV }\end{array}$ & 121 & 4.67998 & 0.01110 \\
\hline $\begin{array}{l}\text { AUTOCARRNOV does not Granger Cause } \\
\text { DDCREDCARRNOVO }\end{array}$ & & 0.77079 & 0.46500 \\
\hline DCREDTOTAL does not Granger Cause AUTOCARRNOV & 123 & 1.49753 & 0.22790 \\
\hline AUTOCARRNOV does not Granger Cause DCREDTOTAL & & 0.35604 & 0.70119 \\
\hline DCREDPIB does not Granger Cause AUTOCARRNOV & 123 & 10.3431 & 7.3E-05 \\
\hline AUTOCARRNOV does not Granger Cause DCREDPIB & & 0.10974 & 0.89616 \\
\hline
\end{tabular}


conclusão...

\begin{tabular}{lccc}
\hline Pairwise Granger Causality Tests & & & \\
\hline Null Hypothesis: & Obs & F-Statistic & Probability \\
\hline DDCREDCARRNOVO does not Granger Cause DTAXJUR & 121 & 0.46677 & 0.62820 \\
DTAXJUR does not Granger Cause & & $\mathbf{6 . 3 0 2 9 2}$ & $\mathbf{0 . 0 0 2 5 2}$ \\
DDCREDCARRNOVO & 122 & 1.09101 & 0.33927 \\
DCREDTOTAL does not Granger Cause DTAXJUR & & 0.05006 & 0.95120 \\
DTAXJUR does not Granger Cause DCREDTOTAL & 122 & 1.22263 & 0.29819 \\
DCREDPIB does not Granger Cause DTAXJUR & & 0.14315 & 0.86677 \\
DTAXJUR does not Granger Cause DCREDPIB & 121 & 1.57396 & 0.21162 \\
DCREDTOTAL does not Granger Cause & & & \\
DDCREDCARRNOVO & & 14.7543 & $2.0 \mathrm{E}-06$ \\
DDCREDCARRNOVO does not Granger Cause & 121 & 0.58624 & 0.55806 \\
DCREDTOTAL & & & \\
DCREDPIB does not Granger Cause & & 0.78087 & 0.46040 \\
DDCREDCARRNOVO & & & \\
DDCREDCARRNOVO does not Granger Cause & 123 & 0.14638 & 0.86398 \\
DCREDPIB & & 0.69515 & 0.50103 \\
\hline DCREDPIB does not Granger Cause DCREDTOTAL & & & \\
DCREDTOTAL does not Granger Cause DCREDPIB & & &
\end{tabular}

Fonte: Extraído do Eviews.

A partir do contexto exposto e levando-se em conta um intervalo de confiança de $95 \%$, bem como os resultados da Tabela 8, pode-se rejeitar a hipótese nula de não causalidade entre as variáveis destacadas em negrito.

Os resultados da Tabela 8 corroboram as demais análises realizadas, dado que há um sentido de causalidade significativo estatisticamente entre preço, volume de financiamentos e as taxas de juros para financiamento em relação à demanda de veículos automotores verificado no período analisado (operações de crédito com recursos livres referenciais para taxa de juros pré-fixada). Pode-se perceber também que há causalidade no sentido de Granger em relação à demanda de veículos e o crédito relacionado aos financiamentos para aquisição destes bens (categoria pré-fixada).

Na Tabela 9, tem-se a análise da decomposição da variância para a demanda de veículos. Nota-se na Tabela 9 que a variação da demanda de veículos (ddemancarrbr) é explicada, em grande medida, pela variável “ddcredcarrnovo", em um patamar máximo de 13,12516 no terceiro período.

Pode-se observar que a própria demanda ("ddemancarrbr") de veículos tem grande impacto sobre a sua própria variação, no valor $17,62 \%$, no terceiro período.

Além disso, pelo método da decomposição da variância dos resíduos pode-se verificar que a taxa de juros mensal para o financiamento de veículos automotores explica até $2,40 \%$ da variação da demanda de veículos no terceiro período. 


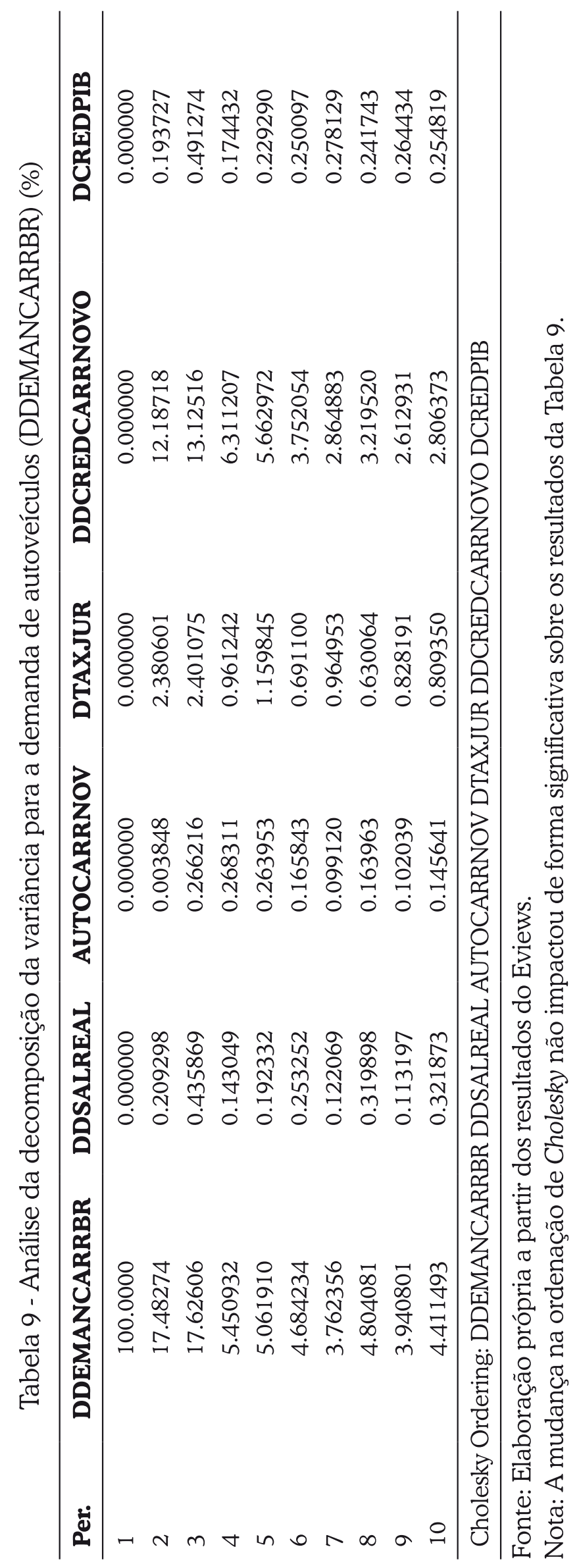




\section{A Demanda de Veículos Automotores no Período Recente: Uma Análise Qualitativa dos Fatores Crédito e Juros}

Na Tabela 10, pode-se observar a evolução do montante de crédito no Sistema Financeiro Nacional (SFN) para o Brasil em relação às pessoas físicas de 2004 a 2010. Pode-se perceber que a porcentagem de Crédito Direto ao Consumidor (CDC) e Leasing em relação ao crédito total para pessoas físicas foi de 10,91\% em setembro de 2010 , ou $33,74 \%$ do total de operações de crédito em relação ao crédito total do Sistema Financeiro Nacional.

Tabela 10 - Montante de crédito no SFN para o Brasil, as pessoas físicas e operações de financiamento de veículos automotores - em bilhões de R $\$$ e \%

\begin{tabular}{|c|c|c|c|c|c|c|}
\hline Ano & $\begin{array}{c}\text { Saldo } \\
\text { de } \\
\text { Crédito } \\
\text { SFN }\end{array}$ & $\begin{array}{c}\text { Total de } \\
\text { Opera- } \\
\text { ções de } \\
\text { Crédito } \\
\text { - Pessoa } \\
\text { Física }\end{array}$ & $\begin{array}{c}\text { CDC e } \\
\text { Leasing } \\
\text { Pessoa } \\
\text { Fisica } \\
\text { (Veículos) }\end{array}$ & $\begin{array}{l}\% \text { - CDC } \\
\text { e Leasing } \\
\text { em relação } \\
\text { ao Crédito } \\
\text { Total do } \\
\text { SFN }\end{array}$ & $\begin{array}{l}\text { \%- Operações } \\
\text { de Crédito } \\
\text { (CDC/Leasing) } \\
\text { em relação ao } \\
\text { total de opera- } \\
\text { ções de crédito }\end{array}$ & $\begin{array}{c}\text { \% - do Total } \\
\text { de Operações } \\
\text { de Crédito } \\
\text { em Relação } \\
\text { ao Crédito } \\
\text { Total da SFN }\end{array}$ \\
\hline 2004 & 498,70 & 138,60 & 42,40 & 8,502 & 6,134 & 27,792 \\
\hline 2005 & 607,00 & 190,70 & 59,10 & 9,736 & 5,106 & 31,417 \\
\hline 2006 & 732,60 & 238,00 & 77,40 & 10,565 & 4,439 & 32,487 \\
\hline 2007 & 936,00 & 317,60 & 111,60 & 11,923 & 3,754 & 33,932 \\
\hline 2008 & 1227,30 & 394,30 & 139,10 & 11,334 & 2,874 & 32,127 \\
\hline 2009 & 1414,20 & 469,80 & 158,20 & 11,187 & 2,381 & 33,220 \\
\hline set./09 & 1348,20 & 451,50 & 152,40 & 11,304 & 2,504 & 33,489 \\
\hline set./10 & 1612,00 & 527,90 & 176,00 & 10,918 & 2,068 & 32,748 \\
\hline
\end{tabular}

Fonte: Elaboração própria a partir de dados do Banco Central do Brasil.

A partir de dados do Banco Central do Brasil e da Associação Nacional das Empresas Financeiras das Montadoras (Anef), referente a setembro de 2010, confirma-se a evolução do CDC como opção de pagamento mais utilizada no escoamento das vendas a prazo de automóveis e comerciais leves, conforme o Gráfico 2.

Até setembro de 2010, a modalidade atingiu 46\% do total de veículos comercializados, enquanto no primeiro trimestre correspondia a $40 \%$ e, no segundo trimestre, a $43 \%$.

Ainda no segmento de veículos e comerciais leves, as operações de Leasing corresponderam a $11 \%$ das vendas a prazo, o Consórcio, por 6\%, e as vendas à vista representaram 37\% em 2010. ${ }^{21}$ Para os outros anos (anteriores a 2004), pode-se observar a importância do financiamento para a aquisição de veículos

21 No segmento de motocicletas, o CDC responde por 52\% das operações, as negociações por Consórcio ficaram em $28 \%$, o leasing, em $1 \%$, e os pagamentos à vista, em $19 \%$. 
no Gráfico 3. Percebe-se mais nitidamente nesse gráfico a relação inversa entre taxa média de juros para financiamento de veículos automotores e vendas mensais desse mesmo bem.

A relação entre a taxa média mensal das operações de crédito para a aquisição de veículos e as vendas mensais no Brasil a correlação de Pearson verificada é bastante elevada, ficando em - 0,758 para as séries do Gráfico 3. Nesse contexto, há uma relação negativa muito forte entre a queda da taxa de juros mensais para aquisição de veículos e suas respectivas vendas mensais (para uma análise econométrica desta variável em relação à demanda agregada de veículos automotores no Brasil, veja a seção 4).

Gráfico 2 - Modalidade de pagamento na venda de veículos e de comerciais leves 2004 ao $3^{\circ}$ trim. 2010

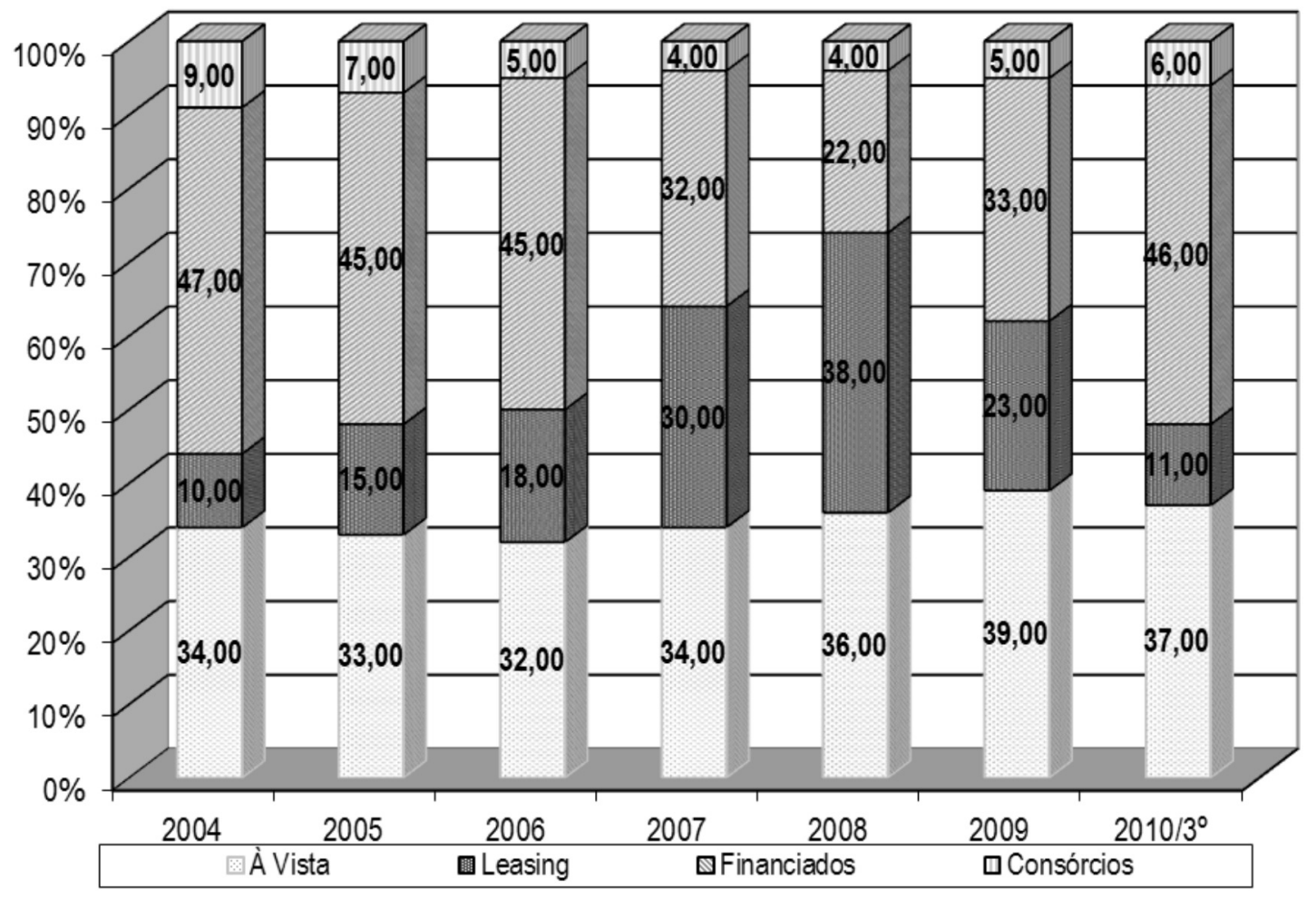

Fonte: Elaboração própria com base nos dados da Anef. 
Gráfico 3 - Taxa média mensal de juros das operações de crédito com recursos livres referenciais para a aquisição de veículos - Pessoa física - \% a.a. e Venda Mensais de

Veículos no Mercado Interno - jun. 2000 a set. 2010

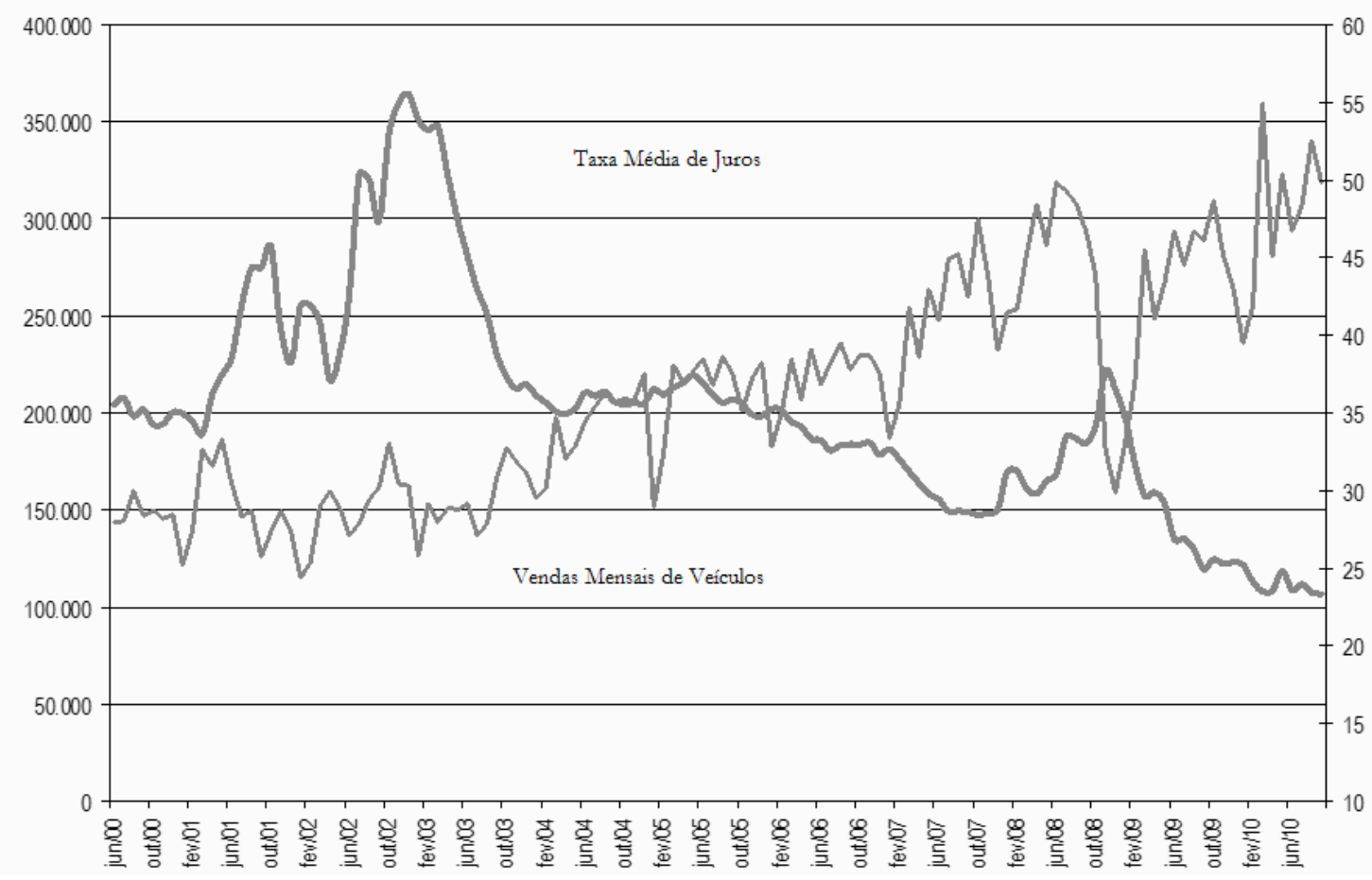

Fonte: Elaboração própria a partir dos dados do Banco Central do Brasil e Anfavea.

No setor de veículos comerciais (caminhões e ônibus), as negociações por Finame lideram com 71\%; o CDC corresponde a 12\%; o Leasing (incluso Finame Leasing), a 5\%; as operações por consórcio, a 2\%; e as vendas à vista, a $10 \%$ de janeiro a setembro de 2010.

O crédito também seguiu em evolução. O saldo total das carteiras de CDC e leasing para aquisição de veículos pelas pessoas físicas atingiu $\mathrm{R} \$ 176$ bilhões em setembro de 2010 . O volume é $15,5 \%$ superior ao registrado em setembro de 2009 , de acordo com os últimos dados consolidados da Anef.

Analisando as carteiras separadamente, o saldo do CDC em setembro de 2010 foi de $\mathrm{R} \$ 125,3$ bilhões, contra $\mathrm{R} \$ 88$ bilhões em setembro de 2009, com alta de 42,5\%. Já o Leasing fechou setembro de 2010 com saldo de R\$ 50,7 bilhões, contra $\mathrm{R} \$ 64,4$ bilhões em setembro de 2009, o que representa um recuo de 21,3\%. Além disso, a taxa de juros mensais para as operações de crédito vem se reduzindo, como se pode observar em relação ao Gráfico 3.

Em relação aos juros, a taxa média praticada pelas afiliadas da Anef foi de $1,44 \%$ ao mês (18,72\% a.a.) em setembro de 2010 , contra $1,45 \%$ ao mês $(18,86 \%$ a.a.) no mesmo período de 2009. Em comparação ao mês de agosto de 2010, a taxa se manteve estável. 
A inadimplência acima de noventa dias para os financiamentos de veículos por meio de CDC continuaram em queda em 2010. O índice fechou setembro daquele ano em 3,1\% ante 4,9\% no mesmo mês do ano anterior. Em comparação ao mês de agosto de 2010 houve também um leve recuo, pois a inadimplência estava em $3,2 \%$.

Os prazos médios para financiamento de veículos foram de aproximadamente 42 meses em setembro de 2010, mantendo o mesmo patamar registrado em setembro de 2009. Pode-se constatar com dados no Banco Central (2010) e Associação Nacional das Empresas Financeiras das Montadoras - Anef (2010) a tendência crescente desses prazos desde 2004, até a crise de liquidez no mercado interno, que se sucedeu no país a partir do início de 2008, o que acabou por encurtar os prazos e encarecer os financiamentos por alguns meses.

\section{Considerações Finais}

Como se pôde observar, a indústria automotiva é extremamente importante em relação à sua influência sobre outras cadeias produtivas. Calcula-se que 50\% do total da borracha, $25 \%$ do total de vidro e $15 \%$ do total de aço produzidos no mundo se destinem à indústria automobilística, de acordo com Casotti e Goldenstein (2008).

De 2000 a 2008, a indústria automotiva brasileira aumentou em $88,35 \%$ sua produção (seção 3). Contudo, de 2000 a 2009, o crescimento da produção de veículos observado tanto na China quanto na Índia ficou muito acima da média dos demais países, sendo este um desempenho condizente com a expansão econômica observada em ambos os países. Se considerada a taxa de crescimento econômico no mesmo período (1997 a 2009), a China cresceu em média 9,02\% a.a, enquanto a Índia obteve um crescimento médio de 6,08\% a.a. (BANCO MUNDIAL, 2010).

Essa dinâmica do setor na China, principalmente, vem moldando novos padrões de concorrência global. Como se constatou na seção 2, países como Brasil sofrerão cada vez mais influência desses países. China e Índia, recentemente, atraíram um grande nível de investimentos e se configuram hoje como dois importantes mercados da indústria automotiva.

Os resultados encontrados para o mercado interno sugerem que o sucesso do aumento de vendas de veículos automotores, entre um conjunto de variáveis testadas por meio do teste de causalidade de Granger, análise de decomposição da variância e regressão, sofreu maior influência dos fatores preço, volume de financiamentos e taxas de juros (operações de crédito com recursos livres referenciais para taxa de juros pré-fixada). No entanto, devem ser levadas em consideração em futuras pesquisas outras variáveis de ordem microeconômica, como marcas, 
rede de concessórias, serviço pós venda, entre outros fatores não destacados no presente artigo.

Conforme argumentado na seção 4, a variável de salário real (proxy mensal para renda) não teve o impacto positivo esperado sobre a demanda de veículos. Entretanto, isso não significa inferir que o nível de renda não foi importante para o consumo dos bens em estudo, como se pode verificar para períodos mais longos com as variáveis de nível de renda per capita e o volume de vendas e produção anual em estudos do CPS/FGV e IEL-PR (2010). Além disso, fazendo-se uma análise ex post dos resultados, pode-se constatar que a variável utilizada não estratificou as mudanças da estrutura de classes sociais verificadas no país recentemente.

\section{Referências}

ASSOCIAÇÃO NACIONAL DOS FABRICANTES DE VEÍCULOS AUTOMOTORES - ANFAVEA. Anuário da indústria automobilística brasileira. São Paulo: Anfavea, 2007.

. Anuário estatístico da Associação Nacional de Fabricantes de Veículos Automotivos. São Paulo: Anfavea, 2007.

. Estatísticas do setor automotivo. 2008. Disponível em: <http://www.anfavea.com. br>. Acesso em: 30 mar. 2008.

ASSOCIAÇÃO NACIONAL DAS EMPRESAS FINANCEIRAS DAS MONTADORAS - ANEF. 2010. Disponivel em: <http://www.anef.com.br $>$.

BAHIA, Luiz D.; DOMINGUES, E. P. Estrutura de Inovações na Indústria Automobilística Brasileira. Rio de Janeiro: IPEA, 2010. (Texto para Discussão, n. 1472).

BANCO CENTRAL. Série histórica sobre operações de crédito. 2008. Disponível em: <http:// www.ipeadata.gov.br>. Acesso em: 28 mar. 2008.

BANCO MUNDIAL. World Development Indicators. 2006. Disponível em: $<$ http://devdata. worldbank.org/wdi2006/contents/cover.htm>. Acesso em: 07 out. 2008.

World Development Indicators. Washington: Banco Mundial, 2007.

BANCO NACIONAL DE DESENVOLVIMENTO ECONÔMICO E SOCIAL - BNDES. Desdobramentos da crise no setor automotivo. Informe Setorial, Rio de Janeiro, n. 10, p. 1-12, mar. 2009. Disponível em: <http://www.bndes.gov.br/SiteBNDES/export/sites/default/bndes_pt/ Galerias/Arquivos/conhecimento/setorial/informe-10AI.pdf > . Acesso em: $\overline{1999 .}$

Polos automotivos brasileiros. BNDES Setorial, Rio de Janeiro, n. 10, p. 173-200,

Reestruturação da indústria automobilística na América do Sul. BNDES Setorial, Rio de Janeiro, n. 14, p. 47-64, 2001.

BRASIL. Ministério do Trabalho e do Emprego. RAIS/MTE. Relação Anual de Informações Sociais. Série histórica disponível em CD pelo Ministério do Trabalho e do Emprego. Brasília, 2006.

CAMARGO, O. S.; LEMOS, M. B. O crescimento da indústria automobilística brasileira e suas implicações para Minas Gerais. In: SEMINÁRIO SOBRE A ECONOMIA MINEIRA, 13., 2008, Diamantina. Anais... Diamantina: [CEDEPLAR/UFMG], 2008. 
CASOTTI, B. P.; GOLDENSTEIN, M. Panorama do setor automotivo: as mudanças estruturais da indústria e as perspectivas para o Brasil. BNDES Setorial, Rio de Janeiro, n. 28, p.147-188, set. 2008.

ENDERS, W. Applied econometric time series. 2nd ed. New York: John Wiley, 2004.

FAGUNDES, J.; PONDE, J. L. Barreiras à entrada e defesa da concorrência: notas introdutórias. Rio de Janeiro: IE/UFRJ, 2001. (Texto de discussão)

FAUTH, K. M.; MORAIS, I. A.; CLEZAR, R. V. O mercado de automóveis, ônibus e caminhões no Brasil, 1996-2008. In: ENCONTRO NACIONAL DE ECONOMIA, 38., 2009, Foz do Iguaçu. Anais... Foz do Iguaçu: ANPEC, 2009.

FENABRAVE/ANFAVEA. Anuário da distribuição de veículos automotores. 2011. Disponível em: <http://www3.fenabrave.org.br:8082/plus>. Acesso em: 7 out. 2008.

FERRAZ, J. C.; KUPFER, D.; HAGUENAUER, L. Made in Brazil, desafios competitivos para a indústria. Rio de Janeiro: Campus, 1996.

FUNDAÇÃO GETÚLIO VARGAS - FGV. Centro de Políticas Sociais - CPS/FGV. Disponível em: $<$ http://cps.fgv.br/>. Acesso em: 07 out. 2008.

INSTITUTO BRASILEIRO DE GEOGRAFIA E ESTATÍSTICA - IBGE. As micro e pequenas empresas comerciais e de serviços no Brasil. 2008. Disponível em: <http://www.ibge.gov.br>. Acesso em: 20 jul. 2008. mar. 2008.

Censo demográfico. 2000. Disponível em: <http://www.ibge.gov.br>. Acesso em: 10

. Pesquisa de Inovação Tecnológica - PINTEC 2005. Rio de Janeiro, 2006. Disponível em: <http://www.pintec.ibge.gov.br/download/manual2005.pdf>. Acesso em: 7 out. 2008.

Pesquisa industrial anual: empresa. Rio de Janeiro: IBGE, 2004. (Série relatórios metodológicos, n. 26). Disponível em: < http://www.ibge.gov.br> . Acesso em: 7 out. 2008.

Série histórica da Pesquisa Nacional por Amostra Domiciliar para os anos de 1992, 1995, 1999, 2001 e 2004. Disponível em: <http://www.ibge.gov.br>. Acesso em: 10 mar. 2008.

INSTITUTO EUVALDO LODI - IEL-PR. Estudo econômico da indústria automobilística. 2. ed. Curitiba: IEL, 2010. (Relatório Interno).

INSTITUTO PARANAENSE DE DESENVOLVIMENTO ECONÔMICO E SOCIAL - IPARDES. Arranjo automotivo da Região Metropolitana sul: Curitiba no Estado do Paraná. Curitiba: IPARDES, 2005.

IPEADATA. Série histórica do sistema de contas nacionais disponibilizada pelo Instituto Brasileiro de Geografia e Estatística. Disponível em <http://www.ipeadata.gov.br $>$. Acesso em: 10 mar. 2008.

ORGANISATION INTERNATIONALE DES CONSTRUCTEURS D'AUTOMOBILES - OICA. Disponivel em: <http://www.oica.net > . Acesso em: 07 out. 2008.

POLÈSE, M. Economia Urbana e Regional: lógica espacial das transformações econômicas. APDR: Coimbra, 1998.

PORSSE, A. A. Multiplicadores de impacto na economia gaúcha: aplicação do modelo de insumo-produto fechado de Leontief. Porto Alegre: FEE, 2002. 
RODRIGUES, R. et al. Transformações na estrutura produtiva da economia paranaense nos anos 80 e 90. Economia Aplicada, São Paulo, v. 11, n. 1, p. 73-93, jan./mar. 2007.

SANTOS, A. M.; PINHÃO, C. M. Pólos automotivos brasileiros. BNDES Setorial, Rio de Janeiro, n.10, p.173-200, set. 1999.

SENHORAS, E. M. A indústria automobilística sob enfoque estático e dinâmico: uma análise teórica. In: SEMINÁRIOS EM ADMINISTRAÇÃO, 8., 2005, São Paulo. Anais... São Paulo: FEA-USP, 2005.

Recebido em: 13/07/2011.

Aceito em: 21/08/2012. 